\title{
The clinical picture of cachexia: a mosaic of different parameters (experience of 503 patients)
}

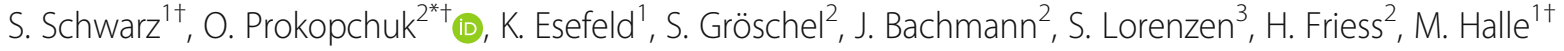 \\ and M. E. Martignoni ${ }^{2+}$
}

\begin{abstract}
Background: Despite our growing knowledge about the pathomechanisms of cancer cachexia, a whole clinical picture of the cachectic patient is still missing. Our objective was to evaluate the clinical characteristics in cancer patients with and without cachexia to get the whole picture of a cachectic patient.

Methods: Cancer patients of the University Clinic "Klinikum rechts der Isar" with gastrointestinal, gynecological, hematopoietic, lung and some other tumors were offered the possibility to take part in the treatment concept including a nutrition intervention and an individual training program according to their capability. We now report on the first 503 patients at the time of inclusion in the program between March 2011 and October 2015. We described clinical characteristics such as physical activity, quality of life, clinical dates and food intake.

Results: Of 503 patients with cancer, 131 patients (26.0\%) were identified as cachectic, 369 (73.4\%) as non-cachectic. The change in cachexia were $23 \%$ reduced capacity performance (108 Watt for non-cachectic-patients and 83 Watt for cachectic patients) and 12\% reduced relative performance $(1.53 \mathrm{Watt} / \mathrm{kg}$ for non-cachectic and $1.34 \mathrm{Watt} / \mathrm{kg}$ for cachectic patients) in ergometry test. $75.6 \%$ of non-cachectic and $54.3 \%$ of cachectic patients still received curative treatment.

Conclusion: Cancer cachectic patients have multiple symptoms such as anemia, impaired kidney function and impaired liver function with elements of mild cholestasis, lower performance and a poorer quality of life in the EORTC questionnaire. Our study reveals biochemical and clinical specific features of cancer cachectic patients.
\end{abstract}

Keywords: Cancer cachexia, Clinical parameters, Clinical picture

\section{Background}

Ongoing cachexia represents a significant factor affecting the quality of life and prognosis of cancer patients. Cachexia is present in up to $40 \%$ in early stages of patients with gastrointestinal cancers and may be involved in up to $80 \%$ cancer deaths. However, it is still difficult to identify cachectic patients, as $40-60 \%$ of cancer patients are overweight or obese, even in advanced cancer [1].

But what do we know about clinical features of cachexia patient?

\footnotetext{
* Correspondence: olga.prokopchuk@tum.de

${ }^{\dagger}$ Equal contributors

${ }^{2}$ Department of Surgery, Klinikum rechts der Isar, Technical University,

Munich, Germany

Full list of author information is available at the end of the article
}

Cachectic patients usually but not always demonstrate lower body mass index (BMI), which is associated with an increased risk of tumor progression [2,3]. At the same time, other groups report that BMI is not a prognostic factor for cancer cachexia in a cohort of patients with 17\% obese, 35\% overweight, 36\% normal weight, and 12\% underweight persons [4]. Cancer cachectic patients experience numerous complications including reduced effectiveness of chemotherapy [5, 6], reduced mobility, and reduced functionality of muscle-dependent systems, such as the respiratory and cardiovascular systems, leading to decreased quality of life and survival [7-9]. Especially in older population, cancer cachexia clinical features are key predictors of one-year mortality [10]. There is a strong correlation between decreased quality of life scores and 
decreased physical activity, which is strongly related to weight loss [11]. It was demonstrated that cachectic patients present lower protein, albumins, and hemoglobin levels [12].

Notably, cachexia is not an incurable situation. The important message is that weight-losing patients with unresectable pancreatic cancer can attenuate their weight loss after eight weeks of intensive nutrition intervention, and weight stabilization is associated with prolonged survival and improved quality of life [13]. However, despite our growing knowledge about the pathomechanisms of this symptom complex, a whole picture of the cachectic patient is still missing.

Some studies aim to define diagnostic criteria of cancer cachexia [14]. Usually, diagnostic tools for cachexia include loss of weight and lean body mass, fatigue, anorexia, reduced physical performance (for example, total activity or 6-min walk distance) and biochemical abnormalities of c-reactive protein (CRP), albumin, and protein.

The existing concepts for the therapy of cachexia are focusing either on nutrition or physical activity. Therefore we founded a nutrition and exercise center for cancer patients in which we are focusing on the definition of the cachectic patient and combined treatment of cancer cachexia with numerous therapy options. Our aim was to evaluate the clinical characteristics such as physical activity, quality of life, clinical dates and food intake in patients with and without cachexia to get the whole picture of a cachectic patient.

\section{Patients}

From March 2011 cancer patients of the University Clinic, "Klinikum rechts der Isar" with gastrointestinal (GI), gynecological, hematopoietic, lung and some other tumors were offered the possibility to take part in the treatment concept including a nutrition intervention and an individual training program according to their capability. We now report on the first 503 patients at the time of inclusion in the program. All parameters like physical capability, daily calorie intake or selected lab values were documented in a prospectively designed database.

The exact definition of cachexia is a debatable issue in medical literature (reviewed in [15]). We used the definition of malnutrition proposed by ESPEN (the European Society for Clinical Nutrition and Metabolism) Consensus Statement using following criteria [16]:

Weight loss (unintentional) $>10 \%$ indefinite of time, or $>5 \%$ over the last three months combined with either

- BMI $<20 \mathrm{~kg} / \mathrm{m} 2$ if $<70$ years of age, or $<22 \mathrm{~kg} / \mathrm{m} 2$ if $>70$ years of age or

- FFMI (fat-free mass index) $<15$ and $17 \mathrm{~kg} / \mathrm{m} 2$ in women and men, respectively.
Our definition of cachexia was also according to Fearon and co-workers [17] and is used by other researchers [18]. Here, the patients are defined as having cachexia, either when they show a weight loss of $5 \%$ during the last six months, or a weight loss of $2-5 \%$ in combination with a $\mathrm{BMI}<20$, or a weight loss of $2-5 \%$, together with the presence of sarcopenia. Sarcopenia was defined according to a report of the European working group on sarcopenia in older people (EWGSOP) using first criterion (low muscle mass) plus either second criterion (low muscle strength) or third criterion (low muscle performance) [19, 20].

\section{Methods \\ Laboratory parameters}

Blood tests (red blood cells and white blood cells counts, platelets, hemoglobin concentrations), serum electrolytes, serum creatinine, c-reactive protein (CRP), liver function tests (aspartate aminotransferase, alanine aminotransferase, alkaline phosphatase, serum bilirubin, and cholinesterase), coagulation tests, and serum albumin levels are routinely performed upon admission to the clinic.

\section{Performance}

Endurance capacity, maximal power output (POmax) and peak oxygen uptake (VO2peak) were measured as described [21] in a submaximal incremental exercise test on a computer-controlled bicycle ergometer. A stepwise incremental exercise protocol was applied starting at 25 or 50 watts with increments of 25 watts every three minutes until volitional exhaustion or medical reasons for exercise termination were reached. The exercise was terminated prematurely in the case of significant ECG abnormalities, severe dyspnea or excessive blood pressure increase to more than $230 \mathrm{mmHg}$ systolic and/or less than $110 \mathrm{mmHg}$ diastolic.

\section{Lung function}

Spirometry provided a measurement of the forced vital capacity (FVC) and the forced expiratory volume at the end of the first second of forced expiration $\left(\mathrm{FEV}_{1}\right)$.

\section{Quality of life and mental health}

Health-related quality of life (HRQoL) is important parameter which can predict survival. It was assessed with the 36-Item Short Form Health Survey SF-36 survey and EORTC QLQ-C30. The EORTC QLQ-C30 is a HRQoL measure specific to cancer, whereas the SF- is a generic measure $[22,23]$. The EORTC QLQ-C30 is a cancerspecific measure that can capture patients' functional status in several domains (physical, psychological, and social), their global health status/quality of life (QoL), and symptom severity $[22,23]$. 


\section{Mental health}

The Hospital Anxiety and Depression Scale (HADS) was used for identifying distress. There are two subscales: depression (HADS-D) and anxiety (HADS-A). The optimal cut-off point is to be $\geqslant 8$ for the identification of suspicious cases and $\geqslant 11$ for safe cases on both subscales, with a sensitivity and specificity of 0.80 on an average [24]. With a score of $\geqslant 13$, it is possible to detect $76 \%$ of the cases among cancer patients with a specificity of 0.60 , whereas $95 \%$ of the cases can be detected with a score of $\geqslant 6$ (specificity 0.21 ) [24].

\section{Nutritional risk screening (NRS)}

A diet record was performed to register food intake (number of meals, calories intake/day, number and kind of additional nutrition) as described [25].

\section{Role of the funding source}

The study was in part supported by Nutricia.

\section{Statistical analysis}

Results are expressed as median values. Statistical analyses were performed using the SPSS (version 23, SPSS Inc., Chicago) software package. Two-sided tests and a significance level of 0.05 were used. Values were compared by Mann-Whitney $U$ test for independent samples.

\section{Results}

The parameters of the patients are noted in Table 1. One hundred thirty-one patients $(26.0 \%)$ were classified as cachectic, $369(73.4 \%)$ as non-cachectic (Fig. 1). In 3 patients $(0.6 \%)$ this information was not available. As expected, cachectic patients showed pronounced weightloss and lower values for BMI, nutrition score and Karnofsky-Index (Table 2). 54.3\% of cachectic patients still receive curative treatment (Fig. 2).

Table 1 Characteristics of cancer patients in the analysis of cachexia

\begin{tabular}{|c|c|c|c|c|}
\hline & \multicolumn{4}{|l|}{ Cachexia } \\
\hline & \multicolumn{2}{|l|}{ no } & \multicolumn{2}{|l|}{ yes } \\
\hline & number & $\%$ & number & $\%$ \\
\hline Gl tumors & 73 & $49,7 \%$ & 74 & $50,3 \%$ \\
\hline Gynecological tumors & 208 & $89,3 \%$ & 25 & $10,7 \%$ \\
\hline Hematopoetic tumors & 39 & $84,8 \%$ & 7 & $15,2 \%$ \\
\hline Lung tumors & 11 & $61,1 \%$ & 7 & $38,9 \%$ \\
\hline Urological tumors & 20 & $83,3 \%$ & 4 & $16,7 \%$ \\
\hline others & 18 & $56,3 \%$ & 14 & $43,8 \%$ \\
\hline
\end{tabular}

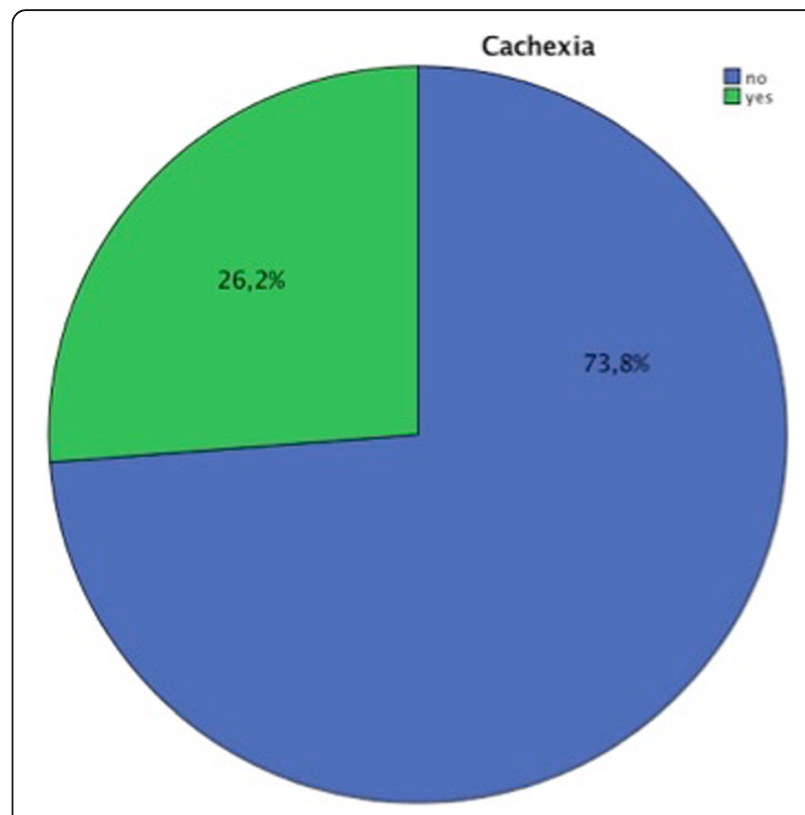

Fig. 1 Distribution of cachectic and non-cachectic in study cohort

\section{Laboratory variables Anemia parameters}

In our study hemoglobin, erythrocytes and hematocrit were significantly $(p<0.001)$ lower in cachectic patients (Table 3). Excluding patients who received chemotherapy at the time of evaluation or prior evaluation, the significant difference $(p=0.015)$ in hemoglobin level is still present $(13.2 \pm 1.3 \mathrm{~g} / \mathrm{dl}$ for non-cachectic patients and $12.5 \pm 1.5 \mathrm{~g} / \mathrm{dl}$ for cachectic patients).

\section{Serum albumin und protein values}

Serum albumin and serum protein were significantly decreased $(p<0.001)$ in cancer patients with cachexia (Table 3).

Table 2 Physical performance of the patients

\begin{tabular}{llll}
\hline & \multicolumn{2}{l}{ Cachexia } & \\
\cline { 2 - 4 } & no & yes & $p$ \\
& Median & Median & \\
\hline BMI [kg/m2] & 24,6 & 20,9 & $<0.001$ \\
Nutritional Risk Score & 1 & 3 & $<0.001$ \\
FEV1 [I] & 2,80 & 2,76 & 0.616 \\
vital capacity [l] & 3,5 & 3,4 & 0.688 \\
IST capacity [\%] & 106 & 96 & $<0.001$ \\
ergometry [Watt] & 108 & 83 & $<0.001$ \\
rel. performance [W/kg KG] & 1,53 & 1,34 & 0.008 \\
maximal heart frequency [/min] & 153,0 & 145,5 & 0.070 \\
Karnofsky-Index [\%] & 9 & 8 & $<0.001$ \\
\hline
\end{tabular}




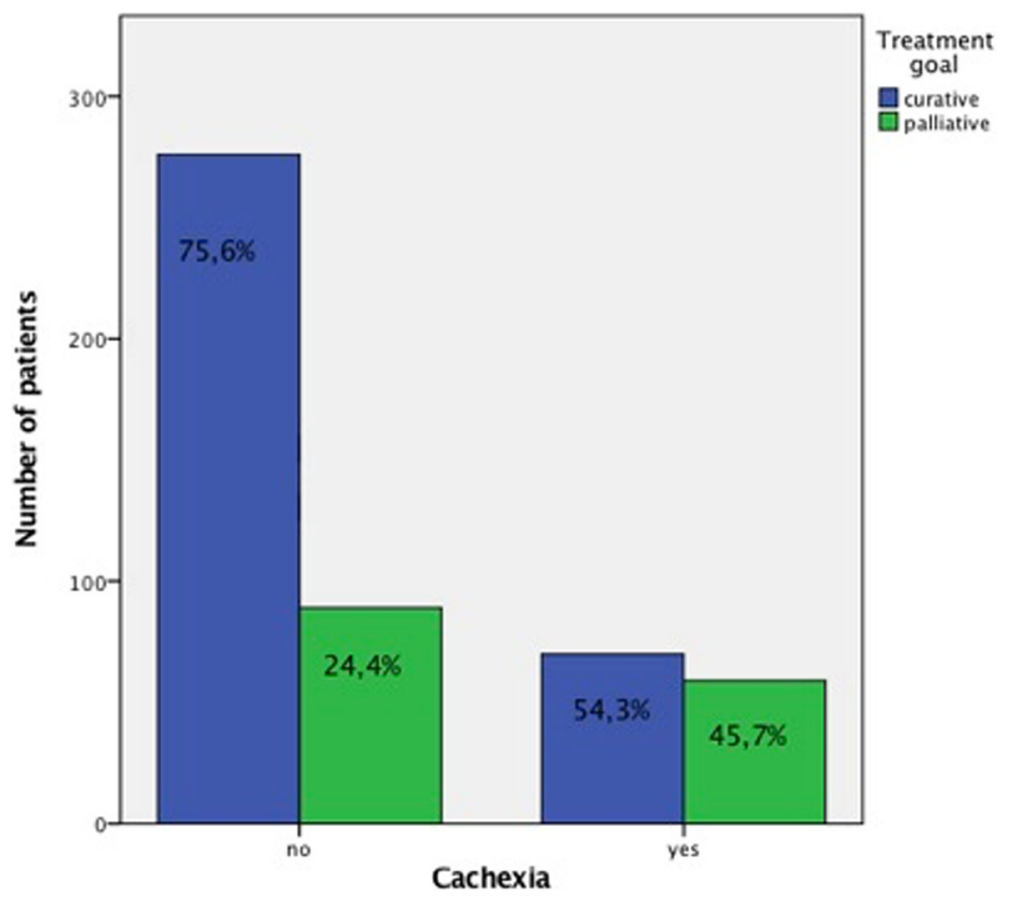

Fig. 2 Possibility of curative treatment in cachectic patients

\section{Kidney function}

Both, median $(0.8 \mathrm{mg} / \mathrm{dl}$ for non-cachexia and $0.8 \mathrm{mg} / \mathrm{dl}$ for cachexia, Table 3) and mean $(0.85 \pm 0.24 \mathrm{mg} / \mathrm{dl}$ for non-cachexia and $0.79 \pm 0.19 \mathrm{mg} / \mathrm{dl}$ for cachexia) serum creatinin values were significantly lower in cachexia group ( $p=0.042$ for medians and $p=0.009$ for means). Urinary creatinine, as well as urinary values for IgG, alpha-1-microglobulin and protein were significantly higher in cachectic patients (Table 4).

\section{Liver function and parameters of protein synthesis}

Two cholestasis enzymes, alkaline phosphatase (ALP) and gamma glutamyl transpeptidase (GGT), were significantly increased in cancer patients with cachexia (Table 3). The parameters of hepatocyte integrity, aspartate aminotransferase (AST) and alanine aminotransferase (ALT), were not changed. Markers of liver synthesis function cholinesterase $(\mathrm{CHE})$, serum albumin and serum protein, were significantly decreased $(p<0.001)$. Totally, 187 patients

Table 3 Selected laboratory blood parameters of cancer patients in the analysis of cachexia

\begin{tabular}{|c|c|c|c|c|c|c|c|}
\hline & \multicolumn{3}{|l|}{ Cachexia } & & \multicolumn{3}{|l|}{ Cachexia } \\
\hline & no & yes & $p$ & & no & yes & $p$ \\
\hline & median & median & & & median & median & \\
\hline Sodium [mmol//] & 141 & 140 & 0.007 & Calcium [mmol//] & 2,39 & 2,33 & $<0.001$ \\
\hline Kalium [mmol/l] & 4,4 & 4,4 & 0,237 & Albumin [g/dl] & 4,50 & 4,30 & $<0.001$ \\
\hline Creatinine $[\mathrm{mg} / \mathrm{dl}]$ &, 8 & 8 & 0,042 & CRP $[\mathrm{mg} / \mathrm{dl}]$ & 1 &, 2 & 0.019 \\
\hline Urea $[\mathrm{mg} / \mathrm{dl}]$ & 14 & 15 & 0,217 & Triglycerides [mg/dl] & 113 & 108 & 0.215 \\
\hline AP [U/I] & 70 & 87 & $<0.001$ & Glucose [mg/dl] & 93 & 94 & 0.452 \\
\hline Bilirubin [mg/dl] &, 4 &, 4 & 0,242 & Quick [\%] & 100 & 98 & 0.167 \\
\hline GGT [U/I] & 23 & 35 & $<0.001$ & Leukocytes [G/l] & 5,39 & 6,03 & 0.054 \\
\hline GPT (ALAT) & 25 & 26 & 0.670 & Erythrocytes [T/I] & 4,3 & 4,0 & $<0.001$ \\
\hline GOT (ASAT) & 27 & 29 & 0.753 & Hemoglobin [g/dl] & 13,1 & 12,0 & $<0.001$ \\
\hline Cholinesterase [U/I] & 7792 & 6703 & $<0.001$ & Hematocrit [\%] & 38,5 & 35,8 & $<0.001$ \\
\hline LDH [U/l] & 219 & 208 & 0.118 & Thrombocytes [G/l] & 232 & 243 & 0.150 \\
\hline Protein [g/dl] & 7,0 & 6,8 & $<0.001$ & & & & \\
\hline
\end{tabular}


Table 4 Selected urinary parameters of cancer patients in the analysis of cachexia

\begin{tabular}{llll}
\hline & \multicolumn{3}{l}{ Cachexia } \\
\cline { 2 - 4 } & no & yes & $p$ \\
& median & median & \\
\hline Urinary creatinine [mg/dl] & 102 & 169 & 0.001 \\
Urinary albumin [mg/g crea] & 9,9 & 9,9 & 0.053 \\
Urinary protein [mg/g crea] & 77 & 82 & 0,025 \\
Urinary alpha-1-microglobulin [mg/g crea] & 10 & 10 & 0.002 \\
Urinary B-NAG (U/g crea) [U/l] & 5 & 5 & 0.003 \\
Urinary lgG [mg/l] & 4,3 & 6 & $<0.001$ \\
\hline
\end{tabular}

(37\% of all study participants) received chemotherapy at the moment of inclusion in this study, 63 (33.7\%) in cachexia group (this information was not available in 2 of patients) and 124 (66.3\%) patients in non-cachexia group (this information was not available in 4 patients). A significant correlation was seen between AP and current chemotherapy $(r=0.258, P<0.001)$, GGT and current chemotherapy ( $r=0.205, P<0.001)$, as well as CHE and current chemotherapy $(r=-0.182, P<0.001) .66(50.4 \%)$ cachexia and 245 (66.4\%) non-cachectic patients did not receive chemotherapy at the moment of inclusion in this study. In this group there is still a significant difference between cachexia and non-cachexia regarding AP $(p<0.001)$, CHE $(p<0.001)$, Quick $(p<0.05)$ and serum albumin $(p<0.001)$ but not in case of GGT $(p=0.154)$.

\section{Physical performance and lung function}

Three parameters of endurance capacity (absolute and relative performance) were significantly lower in cachectic patients (Table 2).

The FEV1 and VC were not significantly decreased ( $p=0.616$ and $p=0.688$ respectively), and relative VC was significantly lower in cachectic patients (Table 2).

\section{Quality of life, mental health and food intake}

There are significant differences between cachectic, and non-cachectic patients regarding Global Health Score, Physical Functioning Score, Role functioning score, Social functioning score, Fatigue score, Nausea \& vomiting score, Appetite loss score and Diarrhoea score $(p<0.001)$.

\section{Food intake}

Cachectic patients understand the problem of weight loss and take more meals per day as patients without cachexia (Table 5). Cancer patients with cachexia sometimes receive more calories compared to cancer patients without cachexia (Table 6). $12.5 \%$ of cachectic patients receive already parenteral nutrition.

A summary of the clinical parameters of the cachectic cancer patient is shown in Fig. 3.

\section{Discussion}

Our study demonstrated that cancer cachectic patients have multiple symptoms such as anemia, impaired kidney function and impaired liver function along with elements of mild cholestasis. Cachexia patients have low level of protein and albumin. As a result significantly more extracellular water and less intracellular water, compared to patients without cachexia. This means that not only low calories but also low oncotic pressure because of low protein play an important role in weight loss in cachectic patients. In parallel to protein deficiency, cachectic patients have lower performance parameters. The low levels of serum albumin, hematocrit, and fibrinogen are well-known for cachectic patients but probably not specific. Furthermore, the performance status of cachectic patients - measured by ergometry - was significantly reduced, leading to a poorer quality of life in the EORTC questionnaire (Fig. 3).

Fearon and co-workers described a population consisting of 170 advanced pancreatic cancer cachectic patients using Karnofsky Performance Score, grip strength, dietary intake, quality-of-life assessment with EuroQol EQ5D and QLQ-C30, CRP, and CA19-9, but they were mostly concentrated on evaluation whether a 3-factor profile incorporating weight loss, low food intake, and systemic inflammation might relate better to a patient's overall prognosis than will weight loss alone [14]. Wallengren and co-workers report on 405 patients about cachexia criteria like body mass index (BMI), weight loss, fatigue, Karnofsky performance score, physical function measured on a treadmill, low handgrip strength, lean tissue depletion (DXA or arm muscle circumference), quality of life measured by QLQ-C30 and abnormal biochemistry (inflammation, anemia, or low serum albumin) [26]. The biggest data set with 8160 patients was reported by Martin and co-workers [3], but the authors were mainly focused on BMI and \% weight loss about overall survival to develop a grading system. Takayama and co-workers analyzed 406 stage IV NSCLC patients using handgrip strength, quality of life, Karnofsky Performance Scale, biochemical parameters (white blood cell count, hemoglobin, protein, albumin, triglycerides, calcium, CRP, and Insulinlike growth factor-1) and survival [27]. In the study of Theresen and co-workers 77 patients with advanced colorectal carcinoma were described using clinical parameters such as energy intake, the skeletal muscle mass crosssectional area, a tool for assessing nutritional status the Subjective Global Assessment (SGA), protein, albumin and CRP [18].

\section{Laboratory variables Anemia parameters}

In our study population, the median hemoglobin was $12 \mathrm{~g} / \mathrm{dl}$ and mean hemoglobin was $11.8 \pm 1.5 \mathrm{~g} / \mathrm{dl}$. Our 
Table $\mathbf{5}$ The number of meals in cancer patients

\begin{tabular}{|c|c|c|c|c|c|}
\hline & & \multicolumn{4}{|l|}{ Cachexia } \\
\hline & & \multicolumn{2}{|l|}{ no } & \multicolumn{2}{|l|}{ yes } \\
\hline & & number & $\%$ & number & $\%$ \\
\hline \multirow[t]{6}{*}{ Calories intake/day } & $<500 \mathrm{kcal} / \mathrm{d}$ & 1 & $0,3 \%$ & 0 & $0,0 \%$ \\
\hline & $500-1000 \mathrm{kcal} / \mathrm{d}$ & 6 & $1,8 \%$ & 9 & $8,0 \%$ \\
\hline & $1000-1500 \mathrm{kcal} / \mathrm{d}$ & 54 & $16,3 \%$ & 21 & $18,8 \%$ \\
\hline & $1500-2000 \mathrm{kcal} / \mathrm{d}$ & 203 & $61,1 \%$ & 55 & $49,1 \%$ \\
\hline & $2000-2500 \mathrm{kcal} / \mathrm{d}$ & 64 & $19,3 \%$ & 23 & $20,5 \%$ \\
\hline & $>2500 \mathrm{kcal} / \mathrm{d}$ & 4 & $1,2 \%$ & 4 & $3,6 \%$ \\
\hline \multirow[t]{5}{*}{ Number of meals/day } & $<3$ & 21 & $6,0 \%$ & 7 & $5,7 \%$ \\
\hline & $3-5$ & 290 & $82,6 \%$ & 75 & $61,0 \%$ \\
\hline & $>5$ & 34 & $9,7 \%$ & 37 & $30,1 \%$ \\
\hline & 4 & 3 & $0,9 \%$ & 0 & $0,0 \%$ \\
\hline & 5 & 3 & $0,9 \%$ & 4 & $3,3 \%$ \\
\hline \multirow[t]{2}{*}{ Additional nutrition } & no & 348 & $96,1 \%$ & 62 & $48,1 \%$ \\
\hline & yes & 13 & $3,6 \%$ & 63 & $48,8 \%$ \\
\hline
\end{tabular}

data regarding anemia in cachectic patients are by other groups. It was additionally reported using univariate Cox proportional hazard regression that hemoglobin was significantly associated with mortality risk [28]. According to CACHEXIA score of Argiles and co-workers [29], a tool for staging cachectic patients, hemoglobin in cachectic patients should be below $12 \mathrm{~g} / \mathrm{dl}$.

\section{Serum albumin und protein values}

Although we observed hypoalbuminemia and hypoproteinemia in cachectic patients, these changes were not severe. Additionally, we observed that calcium level in cachectic patients was lower than in non-cachectic patients. Taking into consideration that half of circulating calcium ions are bound to albumin, this effect resulted probably from hypoalbuminemia. Reasons for hypoalbuminemia are usually decreased synthesis, increased degradation, or an increased transcapillary escape rate [30]. We hypothesize that the primary mechanism was decreased synthesis what is supported through decreased liver synthesis function measured using liver cholinesterase (Table 3). At the same time decreased degradation was not observed because urinary albumin was unchanged (Table 4).

According to Consensus Statement of the European Society of Clinical Nutrition and Metabolism (ESPEN), visceral proteins like serum albumin concentrations that are good indicators of disease severity and outcome should not be used for either screening or diagnosis of malnutrition because of a low grade of nutrition specificity [16].

\section{Kidney function}

In our study there was a significant difference in serum creatinine in cachectic and non-cachectic groups that is by data of another working group [31], demonstrating that serum creatinine can be a biomarker of skeletal muscle mass in chronic kidney disease. The urinary excretion of enzymes, in particular, N-acetyl-beta-D-glucosaminidase (NAG) and alpha-1-microglobulin, non-invasive parameters of the renal tubular function, were significantly higher in cachectic patients.

\section{Impaired liver function in cachexia}

Two cholestasis markers, AP and GGT, were raised in cachectic patients in isolation with normal bilirubin. Though non-liver causes of this elevation like bone metastases, hyperparathyroidism, renal impairment and Paget's disease are possible, the combination of two markers makes liver problems more likely. One possible explanation is the hepatotoxic effect of the chemotherapy confirmed by the correlation between AP, GGT, $\mathrm{CHE}$ and chemotherapy at the time of inclusion. The difference in AP, GGT, CHE between chemotherapy patients and chemotherapy-naive patients were not significant in our study. To our knowledge, elevated cholestasis markers and decreased liver synthesis parameters were not described in cancer cachexia until now. This elevation was mild but present in cachexia in patients under chemotherapy and without chemotherapy. Only for cardiac cachexia, it was demonstrated that $60 \%$ of cachectic patients present with abnormal cholestatic parameters [32]. Some authors proposed the importance of the role of liver enzymes in cancer cachexia (reviewed in [33, 34]) when a flow of amino acids from skeletal muscle to the liver occurs and serves for gluconeogenesis and acute-phase protein synthesis. It was suggested that an interaction between the tumor, peripheral blood mononuclear cells, and the liver 
Table 6 Quality of life and mental health

\begin{tabular}{|c|c|c|c|c|c|}
\hline & Cachexia & & & & \\
\hline & no & & yes & & \\
\hline & number & median & number & median & $P$ \\
\hline Global Health Score & 329 & 58 & 116 & 50 & $<0.001$ \\
\hline Physical Functioning Score & 331 & 80 & 117 & 60 & $<0.001$ \\
\hline Role functioning score & 331 & 50 & 113 & 33 & 0.001 \\
\hline Emotional functioning score & 327 & 58 & 114 & 58 & 0.739 \\
\hline Cognitive functioning score & 338 & 83 & 116 & 83 & 0.976 \\
\hline Social functioning score & 331 & 67 & 118 & 50 & $<0.001$ \\
\hline Fatigue score & 330 & 56 & 116 & 67 & $<0.001$ \\
\hline Nausea \& vomiting score & 338 & 0 & 118 & 0 & $<0.001$ \\
\hline Pain score & 327 & 33 & 116 & 33 & 0.211 \\
\hline Dyspnoe score & 339 & 33 & 118 & 33 & 0.908 \\
\hline Insomnia score & 340 & 33 & 118 & 33 & 0.752 \\
\hline Appetite loss score & 338 & 0 & 118 & 33 & $<0.001$ \\
\hline Constipation Score & 337 & 0 & 120 & 0 & 0.639 \\
\hline Diarrhoea score & 338 & 0 & 120 & 0 & $<0.001$ \\
\hline Financial difficulties score & 337 & 0 & 116 & 0 & 0.407 \\
\hline Score HADS depression & 336 & 5 & 118 & 6 & 0.172 \\
\hline Score HADS anxiety & 339 & 7 & 116 & 6 & 0.104 \\
\hline SF36 role - physical & 316 & 75 & 110 & 65 & $<0.001$ \\
\hline SF36 physical role function & 317 & 25 & 112 & 0 & 0.003 \\
\hline SF36 physical pain & 324 & 62 & 114 & 57 & 0.572 \\
\hline SF36 general health & 323 & 57 & 111 & 50 & 0.007 \\
\hline SF36 vitality & 333 & 45 & 114 & 40 & 0.003 \\
\hline SF36 social function & 332 & 69 & 118 & 50 & 0.002 \\
\hline SF36 role-emotional & 313 & 67 & 111 & 67 & 0.397 \\
\hline SF36 physical well-being & 327 & 64 & 111 & 60 & 0.377 \\
\hline
\end{tabular}

may play a central role in the development and regulation of cachexia [35]. The important role of the liver in cancer cachexia was proposed by Lieffers and co-workers [36]. They hypothesized that a viscerally driven cachexia syndrome in patients with colorectal cancer originates from an increase in mass of high-metabolic-rate tissues, such as the liver and spleen.

\section{Inflammation parameters (CRP) in cachexia}

Increased CRP is supposed to be a valid laboratory and clinical marker in cachexia $[5,14,37,38]$. Fearon and co-workers proposed that inclusion of a marker of systemic inflammation (e.g., CRP) in a cachexia stratification system could account for patients with real loss of function also perceiving themselves to have reduced function [14]. Though we saw a significant difference in CRP-value between cachexia and non-cachectic patients. This difference $(0.1 \mathrm{mg} / \mathrm{dl}$ versus $0.2 \mathrm{mg} / \mathrm{dl})$ is nonspecific to provide additional information to the clinician when other accessible markers, such as serum hemoglobin or cholinesterase are considered. In spite of some prognostic scores for the assessment and treatment of cancer cachexia, like the Glasgow Prognostic Score (GPS) [39] or the cachexia score (CASCO) [29], which are based on CRP and albumin values, we agree with Utech and coworkers who suggest that inflammatory markers may not necessarily improve our ability to predict survival when cancer staging, serum albumin, and weight loss history are available [28]. Additionally, we think that CRP is not necessarily a characteristic parameter in cancer cachexia because it is not routinely measured in clinical practice, in Germany usually only if indicated.

\section{Physical performance}

Two parameters of endurance (capacity performance and relative performance) were significantly lower in cachectic patients. The dramatic change in cachexia was $23 \%$ reduced capacity performance (108 Watt for non- 


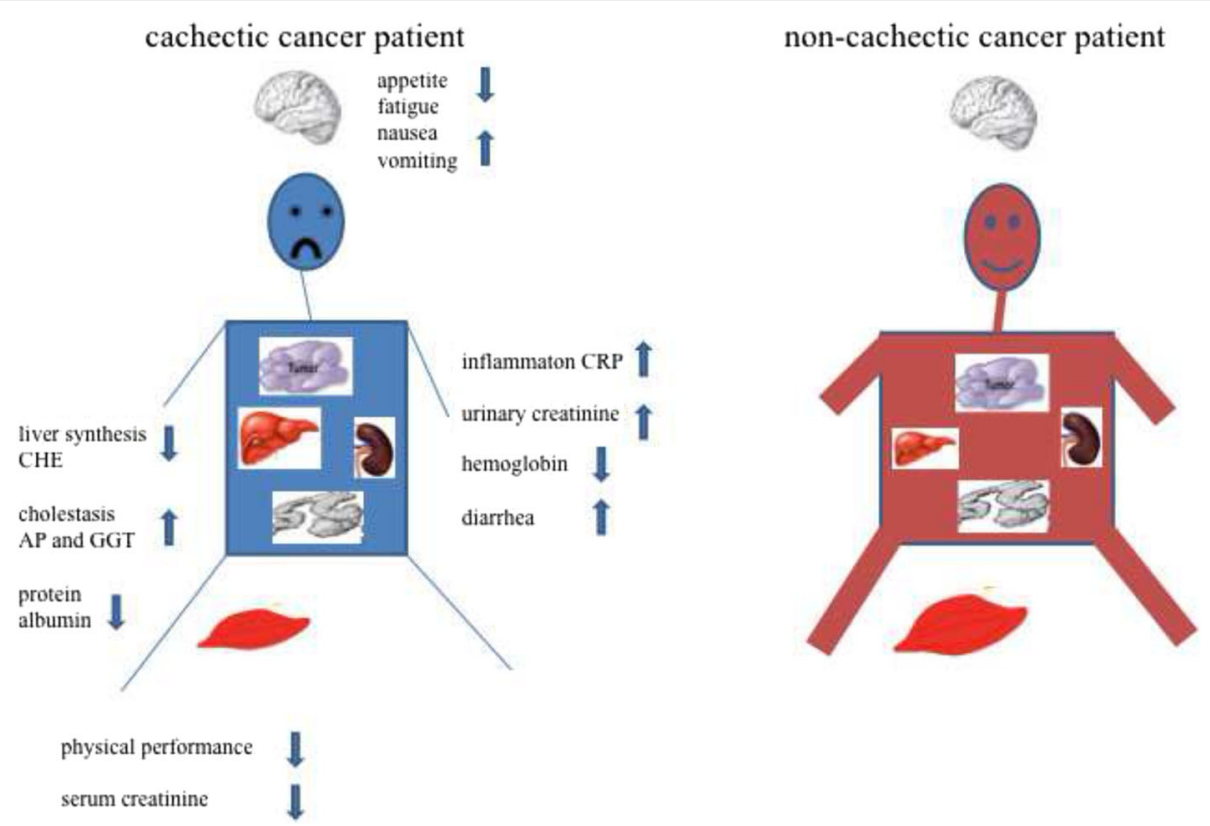

Fig. 3 Schematic clinical picture of the cachectic patient

cachectic-patients and 83 Watt for cachectic patients) and $12 \%$ reduced relative performance $(1.53 \mathrm{Watt} / \mathrm{kg}$ for non-cachectic and $1.34 \mathrm{Watt} / \mathrm{kg}$ for cachectic patients) in ergometry test.

\section{Quality of life, mental health and food intake}

Our results demonstrated that cachexia leads to a reduced quality of life, but the mental health is still stable. The mean value for global quality of life score was $55.7 \pm 20.0$ for non-cachectic patients and $47.7 \pm 21.6$ for cachectic patients, which is worse than the EORTC reference value global score of $61.3 \pm 24.2$ for all cancer types, and worse than values in other studies (for example, $68.73 \pm 19.05$ for patients with different cancer types on chemotherapy [40]).

These data are of special importance because for the EORTC QLQ-C30, both the general health and functioning scales and symptom scales (Dyspnea and Appetite Loss), as well as for the SF-36, role - emotional, general health, energy/vitality, and social functioning significantly predicted survival [23].

Fearon and co-workers report that weight loss alone $(\geq 10 \%)$ did not define a population that differed from self-reported functional aspects of quality of life [14]. With our present study, we were able to demonstrate slight but significant changes in quality of life in cachectic patients without using CRP as a diagnostic parameter for cachexia. This could be explained by the different patient populations (pancreatic cancer patients that were not considered suitable to receive systemic chemotherapy in the study of
Fearon and co-workers, and patients with mixed cancers in our population).

\section{Food intake}

It is supposed that a reduction in food intake is common in patients with progressive cancer and cachexia. Dysphagia, nausea, xerostomia and changes in taste and smell may lead to diminished food intake and thereby insufficient energy intake (reviewed in [1]). Our data show that weight loss didn't depend on calories because cachectic patients know their problem and eat appropriately after a medical recommendation. Additionally, doctors recognize the problem of under-nutrition and prescribe parenteral nutrition (in $12.3 \%$ of patients in our cohort of cachectic patients). Tsoli and colleagues confirm our result in murine model and report that not only reduced food intake but dysregulated expression of transcription factors that control lipid metabolism and thermogenesis in brown adipose tissue lead to weight loss during the development of cachexia [41]. So, despite the same amount of meals per day, patients with cachexia had a reduced calorie intake.

\section{Limitations}

One potential limitation of this study was the observational design, so there may be bias inherent in who ultimately was referred to our nutrition-exercise center or decided to participate in the study. Totally, 187 (37\%) patients received chemotherapy at the moment of inclusion in this study. This fact could influence the characteristics of patients. The patients are inhomogeneous regarding the 
type of cancer. However, future studies should be done in more homogenous cancers patient populations.

\section{Conclusion}

Our study reveals biochemical and clinical specific features of cancer cachectic patients. The positive feature of our study is that it was conducted on large study groups (369 patients without cachexia and 131 patients with cachexia).

We were able to demonstrate that the problem of cachectic patients is not the calorie intake but protein turnover and maybe disorder in fat metabolism. Therefore we postulate that cachectic patients should be treated as high-risk patients and propose that after diagnosis of cachexia the patients should be presented to a cachexia team including "leading doctor" (for, example a surgeon, oncologist or internist, who supervises the treatment), nutritional specialist, clinical pharmacist, sports scientist and psychiatrist.

\section{Abbreviations \\ BMI: Body mass index; CASCO: Cachexia score; CRP: C-reactive protein; $\mathrm{FEV}_{1}$ : Forced expiratory volume at the end of the first second of forced expiration; FVC: Forced vital capacity; Gl: Gastrointestinal; GPS: Glasgow Prognostic Score; HRQoL: Health-related quality of life; POmax: Maximal power output; QoL: Quality of life; VO2peak: Peak oxygen uptake}

\section{Acknowledgements}

Not applicable.

\section{Funding}

This work was supported by in part by Nutricia but the work was independent of it.

\section{Availability of data and materials}

The datasets generated during and/or analysed during the current study are available from the corresponding author on reasonable request.

\section{Authors' contributions}

$\mathrm{OP}, \mathrm{MH}$ and MEM designed and wrote the paper. SS was a physician at nutrition and exercise center and collected clinical information. SG put the data in SPSS. SL, JB, HF, KE, critically reviewed the paper and contributed to the design of the paper. All authors read and approved the final manuscript.

\section{Competing interests}

The authors declare that they have no competing interests.

\section{Consent for publication}

Not applicable.

\section{Ethics approval and consent to participate}

The clinical and laboratory data, as well as training and nutritional parameters are stored in this database pseudonymously and could be used only after the consent of the patient to other scientific purposes. An Institutional Review Board "Ethikkommission der Technischen Universität München" approved the study (Nr. 460/16 s). Written informed consent was obtained from the human subjects

\section{Author details}

${ }^{1}$ Department of Prevention, Rehabilitation and Sports Medicine, Klinikum rechts der Isar, Technical University, Munich, Germany. ${ }^{2}$ Department of Surgery, Klinikum rechts der Isar, Technical University, Munich, Germany. ${ }^{3}$ Department of Hematology and Oncology, Klinikum rechts der Isar, Technical University, Munich, Germany.
Received: 27 October 2016 Accepted: 7 February 2017

Published online: 14 February 2017

\section{References}

1. Ryan AM, Power DG, Daly L, Cushen SJ, Ni Bhuachalla E, Prado CM. Cancerassociated malnutrition, cachexia and sarcopenia: the skeleton in the hospital closet 40 years later. Proc Nutr Soc. 2016;1-13.

2. Renfro LA, Loupakis F, Adams RA, Seymour MT, Heinemann V, Schmoll HJ, et al. Body Mass Index Is Prognostic in Metastatic Colorectal Cancer: Pooled Analysis of Patients From First-Line Clinical Trials in the ARCAD Database. J Clin Oncol. 2016:34(2):144-50.

3. Martin L, Senesse P, Gioulbasanis I, Antoun S, Bozzetti F, Deans C, et al. Diagnostic criteria for the classification of cancer-associated weight loss. J Clin Oncol. 2015;33(1):90-9.

4. Martin L, Birdsell L, Macdonald N, Reiman T, Clandinin MT, McCargar LJ, et al. Cancer cachexia in the age of obesity: skeletal muscle depletion is a powerful prognostic factor, independent of body mass index. J Clin Oncol. 2013;31(12):1539-47.

5. Punzi T, Fabris A, Morucci G, Biagioni P, Gulisano M, Ruggiero M, et al. C-reactive protein levels and vitamin d receptor polymorphisms as markers in predicting cachectic syndrome in cancer patients. Mol Diagn Ther. 2012; 16(2):115-24.

6. Dewys WD, Begg C, Lavin PT, Band PR, Bennett JM, Bertino JR, et al. Prognostic effect of weight loss prior to chemotherapy in cancer patients. Eastern cooperative oncology group. Am J Med. 1980;69(4):491-7.

7. Caillet P, Liuu E, Raynaud Simon A, Bonnefoy M, Guerin O, Berrut G, Lesourd $B$, Jeandel C, Ferry M, Rolland Y, Paillaud E. Association between cachexia, chemotherapy and outcomes in older patients: A systematic review. Clin Nutr. 2016; S0261-5614(16)31344-9.

8. Bachmann J, Heiligensetzer M, Krakowski-Roosen H, Buchler MW, Friess H, Martignoni ME. Cachexia worsens prognosis in patients with resectable pancreatic cancer. J Gastrointest Surg. 2008;12(7):1193-201.

9. Vaughan VC, Martin P, Lewandowski PA. Cancer cachexia: impact, mechanisms and emerging treatments. J Cachex Sarcopenia Muscle. 2013;4(2):95-109.

10. Bourdel-Marchasson I, Diallo A, Bellera C, Blanc-Bisson C, Durrieu J, Germain $C$, et al. One-year mortality in older patients with cancer: development and external validation of an MNA-based prognostic score. PLoS One. 2016;11(2): e0148523.

11. Fouladiun M, Korner U, Gunnebo L, Sixt-Ammilon P, Bosaeus I, Lundholm K Daily physical-rest activities in relation to nutritional state, metabolism, and quality of life in cancer patients with progressive cachexia. Clin Cancer Res. 2007:13(21):6379-85.

12. Bachmann J, Friess H. Martignoni ME: [Molecular mechanisms and its clinical impact in cancer cachexia]. Z Gastroenterol. 2008:46(12):1384-92.

13. Davidson W, Ash S, Capra S, Bauer J. Cancer Cachexia Study G: Weight stabilisation is associated with improved survival duration and quality of life in unresectable pancreatic cancer. Clin Nutr. 2004;23(2):239-47.

14. Fearon KC, Voss AC, Hustead DS. Cancer Cachexia Study G: Definition of cancer cachexia: effect of weight loss, reduced food intake, and systemic inflammation on functional status and prognosis. Am J Clin Nutr. 2006;83(6):1345-50.

15. Mueller TC, Bachmann J, Prokopchuk O, Friess H, Martignoni ME. Molecular pathways leading to loss of skeletal muscle mass in cancer cachexia can findings from animal models be translated to humans? BMC Cancer. 2015;16(1):75

16. Cederholm T, Bosaeus I, Barazzoni R, Bauer J, Van Gossum A, Klek S, et al. Diagnostic criteria for malnutrition - An ESPEN Consensus Statement. Clin Nutr. 2015:34(3):335-40.

17. Fearon K, Strasser F, Anker SD, Bosaeus I, Bruera E, Fainsinger RL, et al. Definition and classification of cancer cachexia: an international consensus. Lancet Oncol. 2011;12(5):489-95.

18. Thoresen L, Frykholm G, Lydersen S, Ulveland H, Baracos V, Prado CM, et al. Nutritional status, cachexia and survival in patients with advanced colorecta carcinoma. Different assessment criteria for nutritional status provide unequal results. Clin Nutr. 2013;32(1):65-72.

19. Bahat G, Tufan A, Tufan F, Kilic C, Akpinar TS, Kose M, et al.: Cut-off points to identify sarcopenia according to European Working Group on Sarcopenia in Older People (EWGSOP) definition. Clinical nutrition 2016

20. Cruz-Jentoft AJ, Baeyens JP, Bauer JM, Boirie Y, Cederholm T, Landi F, et al. Sarcopenia: European consensus on definition and diagnosis: report of the European working group on sarcopenia in older people. Age Ageing. 2010; 39(4):412-23. 
21. Klassen O, Schmidt ME, Scharhag-Rosenberger F, Sorkin M, Ulrich CM, Schneeweiss A, et al. Cardiorespiratory fitness in breast cancer patients undergoing adjuvant therapy. Acta Oncol. 2014;53(10):1356-65.

22. Hays RD, Morales LS. The RAND-36 measure of health-related quality of life. Ann Med. 2001;33(5):350-7.

23. Grande GE, Farquhar MC, Barclay SI, Todd CJ. Quality of life measures (EORTC QLQ-C30 and SF-36) as predictors of survival in palliative colorectal and lung cancer patients. Palliative \& supportive care. 2009;7(3):289-97.

24. Singer S, Kuhnt S, Gotze H, Hauss J, Hinz A, Liebmann A, et al. Hospital anxiety and depression scale cutoff scores for cancer patients in acute care. Br J Cancer. 2009;100(6):908-12.

25. Kondrup J, Rasmussen HH, Hamberg O, Stanga Z, Ad Hoc EWG. Nutritional risk screening (NRS 2002): a new method based on an analysis of controlled clinical trials. Clin Nutr. 2003;22(3):321-36.

26. Wallengren O, Lundholm K, Bosaeus I. Diagnostic criteria of cancer cachexia: relation to quality of life, exercise capacity and survival in unselected palliative care patients. Support Care Cancer. 2013;21(6):1569-77.

27. Takayama K, Atagi S, Imamura F, Tanaka H, Minato K, Harada T, et al. Quality of life and survival survey of cancer cachexia in advanced non-small cell lung cancer patients-Japan nutrition and QOL survey in patients with advanced non-small cell lung cancer study. Supportive care in cancer: official journal of the Multinational Association of Supportive Care in Cancer 2016.

28. Utech AE, Tadros EM, Hayes TG, Garcia JM. Predicting survival in cancer patients: the role of cachexia and hormonal, nutritional and inflammatory markers. J Cachex Sarcopenia Muscle. 2012;3(4):245-51.

29. Argiles JM, Lopez-Soriano FJ, Toledo M, Betancourt A, Serpe R, Busquets S. The cachexia score (CASCO): a new tool for staging cachectic cancer patients. J Cachex Sarcopenia Muscle. 2011;2(2):87-93.

30. Fearon KC, Barber MD, Falconer JS, McMillan DC, Ross JA, Preston T. Pancreatic cancer as a model: inflammatory mediators, acute-phase response, and cancer cachexia. World J Surg. 1999;23(6):584-8.

31. Patel SS, Molnar MZ, Tayek JA, Ix JH, Noori N, Benner D, et al. Serum creatinine as a marker of muscle mass in chronic kidney disease: results of a cross-sectional study and review of literature. J Cachex Sarcopenia Muscle. 2013:4(1):19-29.

32. Valentova M, von Haehling S, Krause C, Ebner N, Steinbeck L, Cramer L, et al. Cardiac cachexia is associated with right ventricular failure and liver dysfunction. Int J Cardiol. 2013;169(3):219-24.

33. Argiles JM, Busquets S, Stemmler B, Lopez-Soriano FJ. Cancer cachexia: understanding the molecular basis. Nat Rev Cancer. 2014;14(11):754-62.

34. Argiles JM, Stemmler B, Lopez-Soriano FJ, Busquets S. Nonmuscle tissues contribution to cancer cachexia. Mediat Inflamm. 2015;2015:182872.

35. Martignoni ME, Dimitriu C, Bachmann J, Krakowski-Rosen H, Ketterer K, Kinscherf $R$, et al. Liver macrophages contribute to pancreatic cancer-related cachexia. Oncol Rep. 2009;21(2):363-9.

36. Lieffers JR, Mourtzakis M, Hall KD, McCargar L, Prado CM, Baracos VE. A viscerally driven cachexia syndrome in patients with advanced colorectal cancer: contributions of organ and tumor mass to whole-body energy demands. Am J Clin Nutr. 2009;89(4):1173-9.

37. Skorokhod A, Bachmann J, Giese N, Martignoni ME, Krakowski-Roosen H. Real-imaging CDNA-AFLP transcript profiling of pancreatic cancer patients: Egr-1 as a potential Key regulator of muscle cachexia. BMC Cancer. 2012; 12(1):265.

38. Batista Jr ML, Peres SB, McDonald ME, Alcantara PS, Olivan M, Otoch JP, et al. Adipose tissue inflammation and cancer cachexia: possible role of nuclear transcription factors. Cytokine. 2012;57(1):9-16.

39. Douglas E, McMillan DC. Towards a simple objective framework for the investigation and treatment of cancer cachexia: the Glasgow prognostic score. Cancer Treat Rev. 2014;40(6):685-91.

40. Vergara N, Montoya JE, Luna HG, Amparo JR, Cristal-Luna G. Quality of life and nutritional status among cancer patients on chemotherapy. Oman Med J. 2013;28(4):270-4.

41. Tsoli M, Moore M, Burg D, Painter A, Taylor R, Lockie SH, et al. Activation of thermogenesis in brown adipose tissue and dysregulated lipid metabolism associated with cancer cachexia in mice. Cancer Res. 2012;72(17):4372-82.

\section{Submit your next manuscript to BioMed Central and we will help you at every step:}

- We accept pre-submission inquiries

- Our selector tool helps you to find the most relevant journal

- We provide round the clock customer support

- Convenient online submission

- Thorough peer review

- Inclusion in PubMed and all major indexing services

- Maximum visibility for your research

Submit your manuscript at www.biomedcentral.com/submit

) Biomed Central 